\title{
Intraportal Glucose Delivery Enhances the Effects of Hepatic Glucose Load on Net Hepatic Glucose Uptake in Vivo
}

Sharon R. Myers, David W. Biggers, Doss W. Neal, and Alan D. Cherrington

Department of Molecular Physiology and Biophysics, Vanderbilt University School of Medicine, Nashville, Tennessee 37232

\begin{abstract}
Although the importance of the hepatic glucose load in the regulation of liver glucose uptake has been clearly demonstrated in in vitro systems, the relationship between the hepatic glucose load and hepatic glucose uptake has yet to be defined in vivo. Likewise, the effects of the route of glucose delivery (peripheral or portal) on this relationship have not been explored. The aims of the present study were to determine the relationship between net hepatic glucose uptake (NHGU) and the hepatic glucose load in vivo and to examine the effects of the route of glucose delivery on this relationship. NHGU was evaluated at three different hepatic glucose loads in 42-h fasted, conscious dogs in both the absence $(n=7)$ and the presence ( $n$ $=6$ ) of intraportal glucose delivery. In the abscence of intraportal glucose delivery and in the presence of hepatic glucose loads of $50.5 \pm 5.9,76.5 \pm 10.0$, and $93.6 \pm 10.0 \mathrm{mg} / \mathrm{kg} / \mathrm{min}$ and arterial insulin levels of $\sim 33 \mu \mathrm{U} / \mathrm{ml}$, NHGU was $1.16 \pm 0.37$, $2.78 \pm 0.82$, and $5.07 \pm 1.20 \mathrm{mg} / \mathrm{kg} / \mathrm{min}$, respectively. When a portion of the glucose load was infused into the portal vein and similar arterial insulin levels $(\sim 36 \mu \mathrm{U} / \mathrm{ml})$ and hepatic glucose loads $(52.5 \pm 4.5,70.4 \pm 5.6$, and $103.6 \pm 18.4 \mathrm{mg} / \mathrm{kg} / \mathrm{min})$ were maintained, NHGU was twice that seen in the absence of portal loading $(3.77 \pm 0.40,4.80 \pm 0.59$, and $9.62 \pm 1.43 \mathrm{mg} / \mathrm{kg} /$ min, respectively). Thus, net hepatic glucose uptake demonstrated a direct dependence on the hepatic glucose load that did not reach saturation even at elevations in the hepatic glucose load of greater than three times basal. In addition, the presence of intraportal glucose delivery increased net hepatic glucose uptake apparently by lowering the threshold at which the liver switched from net glucose output to net glucose uptake. ( $J$. Clin. Invest. 1991. 88:158-167.) Key words: glucose • hepatic glucose uptake • portal glucose.
\end{abstract}

\section{Introduction}

The importance of the hepatic glucose load in the regulation of glucose uptake by the liver has been assumed since the time of Claude Bernard (1). Although experiments carried out in in vitro systems have shown that net hepatic glucose uptake, net glycogen deposition, and the activities of glycogen synthase

Address correspondence to Dr. A. D. Cherrington, Department of Molecular Physiology \& Biophysics, Vanderbilt University School of Medicine, Nashville, TN 37232-0615. S. R. Myer's current address is Lilly Research Laboratories, Eli Lilly and Co., Indianapolis, IN 46285.

Received for publication 26 October 1990 and in revised form 1 February 1991.

J. Clin. Invest.

(c) The American Society for Clinical Investigation, Inc.

0021-9738/91/07/0158/10 \$2.00

Volume 88, July 1991, 158-167 and phosphorylase are affected by glucose in a dose-dependent manner (2-6), a dose-response relationship between the hepatic glucose load and net hepatic glucose uptake has yet to be defined in vivo. Early in vivo work carried out in the $\operatorname{dog}(7,8)$ strongly supported the existence of a direct relationship between net hepatic glucose uptake and the hepatic glucose load, but since the pancreatic response to hyperglycemia was not controlled in these studies, the role of the glucose load in eliciting the observed effects could not be differentiated from that of insulin.

More recent studies using diabetics (9) and somatostatintreated nondiabetics (10-16) have clearly demonstrated the ability of hyperglycemia to suppress both total and net hepatic glucose production in the absence of a rise in insulin, but have failed to demonstrate an ability of hyperglycemia per se to cause net splanchnic (man) or hepatic (dog) glucose uptake. Since significant net splanchnic glucose uptake $(13,17,18)$ and net hepatic glucose uptake (19-21) have been reported to occur in man and dog in the presence of combined hyperinsulinemia and hyperglycemia, it is apparent that insulin must also be elevated for net glucose uptake to occur.

In the most recent attempt to determine the effects of elevations in glucose on hepatic glucose uptake, DeFronzo et al. (15) measured net splanchnic glucose uptake in man at three different arterial plasma glucose levels (137, 224, and $395 \mathrm{mg} / \mathrm{dl})$. As with the earlier studies, a dose-dependent relationship was evident, but because insulin values were not controlled, it was unclear to what extent the changes in splanchnic glucose uptake were due to alterations in the glucose level, the insulin level, or a synergism of the two.

In the experiments cited above, hyperglycemia was maintained by infusing glucose solely into a peripheral vein. Results from recent studies suggest that glucose uptake by the liver is influenced by the route of glucose delivery as well as the glucose and insulin levels. DeFronzo et al. (17) reported a sixfold increase in net splanchnic glucose uptake ( $1.0 \mathrm{vs} .5 .9 \mathrm{mg} / \mathrm{kg} / \mathrm{min}$ ) when an oral glucose load was added to a peripheral glucose infusion in man. Ferrannini et al. (18), also working with man, observed a 3.4-fold increase in net splanchnic glucose uptake (from 1.2 to $4.1 \mathrm{mg} / \mathrm{kg} / \mathrm{min}$ ) when glucose was ingested rather than infused into a peripheral vein. Ishida et al. (19) working with the dog found that the increase in uptake of glucose by the liver during absorption of an oral glucose load could be mimicked by infusion of glucose directly into the portal vein (7.3 and $6.9 \mathrm{mg} / \mathrm{kg} / \mathrm{min}$, respectively). They also showed that intraportal glucose delivery was associated with a sixfold greater increase in net hepatic glucose uptake than was evident when glucose was infused via a peripheral vein $(1.0 \mathrm{vs.} 6.0 \mathrm{mg} / \mathrm{kg} /$ min). Similarly, Barrett et al. (20) and Bergman et al. (22) found that net hepatic glucose uptake in the dog was indistinguishable during oral and intraportal glucose delivery. Barrett et al. (20) also found slightly greater net hepatic glucose uptake during oral glucose delivery than during peripheral glucose ad- 
ministration $(3.4$ and $2.8 \mathrm{mg} / \mathrm{kg} / \mathrm{min}$ during oral and peripheral glucose administration, respectively) even though portal vein insulin concentrations in the peripheral glucose studies were 2.2-fold greater than those in the oral glucose experiments. Studies by Adkins et al. $(16,21)$ demonstrated not only that intraportal glucose delivery can enhance liver glucose uptake during moderate elevations in the plasma insulin level but also that it can cause net hepatic glucose uptake $(1.4 \mathrm{mg} / \mathrm{kg} /$ $\mathrm{min}$ ) even in the presence of basal insulin levels, a situation in which peripheral glucose delivery can only suppress hepatic glucose production.

In light of the above findings the aims of the present study were $(a)$ to determine the relationship between the hepatic glucose load and net hepatic glucose uptake with the insulin level precisely controlled and $(b)$ to determine the effects of the route of glucose delivery on this relationship.

\section{Methods}

Animals and surgical procedures. Experiments were carried out on mongrel dogs (16-28 $\mathrm{kg}$ ) of either sex that had been fed a meat and chow diet (31\% protein, $52 \%$ carbohydrate, $11 \%$ fat, and $6 \%$ fiber based on dry weight; Kal Kan meat, Kal Kan Foods, Inc., Vernon, CA and Wayne Dog Chow, Allied Mills, Inc., Chicago, IL) once daily for 2 wk and that had been without food for $42 \mathrm{~h}$. The protocols were approved by the Vanderbilt Medical School Animal Care Committee and the care of the dogs complied with the AAALAC regulations. $16 \mathrm{~d}$ before the experiment, a laparotomy was performed under general anesthesia (sodium pentobarbitol, $25 \mathrm{mg} / \mathrm{kg}$ ), during which time "Silastic" catheters were inserted into a splenic vein, a jejunal vein, a colic vein, the gastroduodenal vein, the portal vein, and the left common hepatic vein. The tips of the splenic, jejunal, colic, and gastroduodenal catheters were placed $1 \mathrm{~cm}$ beyond the first site of coalescence of the catheterized vein with another vessel. The tip of the portal vein catheter was placed $2 \mathrm{~cm}$ distal to the point at which the vessel enters the liver, and the tip of the hepatic vein catheter was placed $1 \mathrm{~cm}$ inside the left common hepatic vein. A fifth catheter was inserted into the left femoral artery following a cut-down in the inguinal region. After insertion, the catheters were filled with saline-containing heparin $(200 \mathrm{U} / \mathrm{ml}$; Abbott Laboratories, North Chicago, IL), and their free ends were knotted. The free ends of the catheters were then placed in subcutaneous pockets to allow complete closure of the incisions. $2 \mathrm{wk}$ after surgery blood was drawn to determine the leukocyte count and the hematocrit of the animal. Only animals that had $(a)$ a leukocyte count below 18,000 / $\mathrm{mm}^{3},(b)$ an hematocrit above $38 \%,(c)$ normal stools, and $(d)$ a good appetite (consuming all of the daily ration) were used.

On the day of the experiment, the free ends of the catheters were exteriorized from the subcutaneous pockets through small incisions made under local anesthesia (2\% Lidocaine). The contents of each catheter were aspirated, and the catheters were flushed with saline. Catheters in the splenic, jejunal, colic, and gastroduodenal veins were used for the intraportal infusion of insulin, glucagon (Eli Lilly, Indianapolis, IN), and glucose, and catheters in the portal vein, hepatic vein, and femoral artery were used for blood sampling. Angiocaths (20gauge, Deseret Medical, Inc., Becton Dickinson and Co., Sandy, UT) were inserted percutaneously into the left cephalic vein for the continuous infusion of indocyanine green dye (Hynson, Westcott and Dunning, Baltimore, MD), into the right cephalic vein for the peripheral infusion of glucose, and into a saphenous vein for the peripheral infusion of paraaminohippurate (PAH) ${ }^{1}$ and somatostatin (Bachem, Inc.,

1. Abbreviations used in this paper: GI, gastrointestinal; NHGB, net hepatic glucose balance; NHGU, net hepatic glucose uptake; PAH, para-aminohippurate; PUG, peripheral uptake of glucose.
Torrance, CA). The dog rested quietly in a Pavlov harness for 20-30 min before the beginning of the experiment and remained there for the duration of the study.

Experimental design. Each experiment in the two protocols consisted of an 80-min dye and tracer equilibration period (0-80 $\mathrm{min}$ ), a 40-min control period (80-120 min, Period I), and three 90-min test periods (120-210 min, period II; $210-300 \mathrm{~min}$, period III; 300-390 min, period IV). Each test period consisted of a 60 -min equilibration period and a 30-min steady-state sampling period during which experimental values were determined. A constant infusion of indocyanine green dye $\left(0.1 \mathrm{mg} / \mathrm{m}^{2} / \mathrm{min}\right)$ was begun at $0 \mathrm{~min}$. In protocol $1\left(P_{\mathrm{e}}\right)$, a peripheral infusion of somatostatin $(0.8 \mu \mathrm{g} / \mathrm{kg} / \mathrm{min})$ and intraportal infusions of insulin $(1.2 \mathrm{mU} / \mathrm{kg} / \mathrm{min})$ and glucagon $(0.65 \mathrm{ng} / \mathrm{kg} / \mathrm{min})$ were started at the beginning of period II to suppress endogenous insulin and glucagon secretion and to maintain a constant three to fourfold elevation in insulin levels and basal glucagon levels. In addition, a primed $(30 \mathrm{mg} / \mathrm{kg} / \mathrm{min}$ peripheral glucose infusion decreased in increments of $5 \mathrm{mg} / \mathrm{kg} / \mathrm{min}$ over a 10 -min period in such a way as to just fill the rapidly equilibrating glucose distribution space and thus quickly raise the blood glucose concentration to the target level), peripheral infusion of glucose (D50) was also begun so as to increase the load of glucose reaching the liver by $\sim 65 \%$. At the beginning of period III and again at the beginning of period IV, the hepatic glucose load was elevated by 140 and $220 \%$ of basal, respectively, through increases in the peripheral glucose infusion rate.

In protocol $2\left(P_{\mathrm{o}}\right)$, a constant peripheral infusion of PAH $(0.4 \mathrm{mg} /$ $\mathrm{kg} / \mathrm{min}$ ) was begun at $0 \mathrm{~min}$ along with the indocyanine green as noted earlier. At the beginning of period II, hormone infusions were begun as in protocol I. A 10-min peripheral glucose (D50) prime and an intraportal glucose/PAH infusion (PAH mixed with D20 in such a way that the PAH infusion rate was $\sim 0.4 \mathrm{mg} / \mathrm{kg} / \mathrm{min}$ ) were initiated to rapidly raise the blood glucose level so that the hepatic glucose load approximated that achieved in the corresponding period of protocol 1 . The peripheral PAH infusion was discontinued at the start of period II. The blood glucose level was maintained constant for the remainder of the period through slight adjustments in the intraportal glucose infusion rate. A peripheral glucose (D50) infusion was started at the beginning of period III and then increased in period IV to raise the hepatic glucose load to the same rate as those used in periods III and IV of protocol 1 without altering the arterial-portal glucose gradient established during period II. The peripheral glucose infusion was adjusted so as to maintain the required arterial glucose level based on estimates of the plasma glucose level made every 5 min.

Each of five dogs was studied using both protocols, the experiments being carried out in a randomized fashion, 2 wk apart. Technical problems (catheter failure, elevated white blood cell count) prevented the performance of a second study in an additional three animals; in these, two dogs were studied using only protocol 1 , and one dog was studied using only protocol 2 . Thus, seven experiments were performed using protocol 1, and six experiments were performed using protocol 2 .

Femoral artery, portal vein, and hepatic vein blood samples were taken every 20 min during period I and every 15 min during the last 30 min of periods II, III, and IV, giving three estimates of hepatic balance for each steady-state period. The collection and immediate processing of blood samples have been described previously (23). The arterial and portal vein blood samples were collected simultaneously, and the hepatic vein sample was collected $\sim 30 \mathrm{~s}$ later to compensate for the transit time of glucose through the liver (24).

Analytical procedures. Six determinations of the glucose concentration were made on each plasma sample using the glucose-oxidase method (25) in a glucose analyzer (Beckman Instruments, Inc., Fullerton, CA). Three glucose and one lactate determination were made on PCA extracts of blood using the Technicon Autoanalyzer II (Technicon Instruments Corporation, Tarrytown, NY) according to the method of Lloyd et al. (26). Blood PAH levels were determined in duplicate on PCA extracts of blood (CV 8\%) using an adaptation of the method developed by Brun (27). Immunoreactive insulin was measured (Interassay CV 8\%) using a double-antibody procedure (28), and 
immunoreactive glucagon concentrations were determined (Interassay CV $11 \%$ ) using the $30 \mathrm{~K}$ antiserum of Unger according to the method of Aguilar-Parada et al. (29) after collection of plasma with Trasylol (500 KIU Trasylol/ml plasma; FBA Pharmaceuticals, New York, NY). Indocyanine green, used in the estimation of hepatic blood flow, was measured spectrophotometrically at $805 \mathrm{~nm}$ according to the method of Leevy et al. (30).

Calculations. Due to the large potential error that incomplete mixing of the intraportally delivered glucose with the hepatic blood supply could introduce to the results (16), a method was devised to detect gross errors in mixing. PAH, a substance not extracted by the liver (verified during peripheral PAH infusion), was mixed with the intraportal glucose infusate, and the recovery of PAH across the liver was measured (recovery $=\mathrm{HBF} \times\left(P A H_{\mathrm{H}}-P A H_{\mathrm{A}}\right)$ where $\mathrm{HBF}$ represents total hepatic blood flow and $P A H_{\mathrm{A}}$ and $P A H_{\mathrm{H}}$ represent arterial and hepatic vein PAH concentrations, respectively). The ratio between the hepatic or portal recovery of intraportally infused PAH and the actual intraportal PAH infusion rate was then calculated and used as an index of mixing of the intraportal infusate with the blood by the time the latter exits the liver. $\mathrm{PAH}_{\mathrm{P}}$ can be substituted for $\mathrm{PAH}_{\mathrm{H}}$ to assess recovery, and thus mixing of PAH in the hepatic portal system, before entry into the liver. Because of the magnitude of the coefficient of variation of the method for assessing PAH balance, samples could be considered statistically "unmixed" (i.e., > 95\% confidence that mixing did not occur) if hepatic or portal recovery of intraportally infused PAH was $40 \%$ greater or less than the actual amount of PAH infused. In 19 experiments in which this approach has been used to evaluate the mixing of glucose in the hepatic blood supply, the infusate failed to mix with the blood only $14 \%$ of the time. More importantly, when mixing errors did occur they were random. In the present study no data were excluded on the basis of poor mixing in view of the quality of mixing and the random nature of the error. Accordingly, the overall recovery of infused PAH on the downstream side of the liver in the present study was $93 \pm 6 \%$ and in the portal vein was $103 \pm 10 \%$, indicating the adequacy of overall mixing.

Because glucose in the canine red cell equilibrates slowly with the glucose in plasma, hepatic glucose balance is most appropriately calculated using whole blood glucose values. Measurement of whole blood glucose values is less accurate than plasma glucose measurement because it requires a PCA deproteinization step and typically allows fewer estimates per sample (in these experiments, three vs. six). To lessen the error introduced into the hepatic glucose balance calculation by the use of whole blood glucose values we determined the A-V difference as accurately as possible using plasma glucose values and then corrected that value to whole blood glucose using a blood glucose/plasma glucose ratio. In each experiment the ratio apparent in each vessel (artery, portal, hepatic) during each of the four periods (I, II, III, IV) was computed and used to calculate the blood glucose A-V difference at each site during each period. Net hepatic glucose balance was calculated using whole blood glucose values directly, as well as using plasma glucose differences corrected to blood glucose differences using the blood/ plasma glucose ratio. With the exception of Table VII, all glucose balance and load data contained in the mean data base were calculated using plasma glucose corrected to blood glucose.

In protocol I, the load of glucose to the gastrointestinal (GI) tract $\left(G L=P B F \times G_{\mathrm{A}}\right.$, where $G_{\mathrm{A}}$ represents the arterial blood glucose concentration and $P B F$ equals portal vein blood flow) and the uptake of glucose by the GI tract $\left(G U G=P B F \times\left(G_{\mathrm{A}}-G_{\mathrm{P}}\right)\right.$, where $G_{\mathrm{P}}$ represents the portal vein blood glucose concentration) were calculated, and the relationship between the two values was determined (GUG $=[0.587$ $\left.\times\left(G L_{\mathrm{T}} / G L_{\mathrm{C}}\right)+0.507\right] \times G U G_{\mathrm{C}}, T$ and $C$ representing values at time $T$ and during the control period, respectively). This relationship was then used for both protocols in the indirect calculation of the hepatic glucose load.

The glucose load to the liver $\left(L O A D_{\text {in }}\right)$ was calculated, as in previous studies $(16,21)$, using two different methods: $(a)$ indirectly according to the equation $L O A D_{\text {in }}=\left(G_{\mathrm{A}} \times H B F\right)+G I R_{\mathrm{P}_{\mathrm{o}}}-G U G$ where $G I R_{\mathrm{P}_{\mathrm{o}}}$ is the intraportal glucose infusion rate and $(b)$ directly as
$\mathrm{LOAD}_{\text {in }}=\left[\left(G_{\mathrm{A}} \times A B F\right)+\left(G_{\mathrm{P}} \times P B F\right)\right]$ where ABF represents the hepatic arterial blood flow. The load of glucose exiting the liver $\left(L O A D_{\text {out }}\right)$ was calculated using the equation $L O A D_{\text {out }}=G_{\mathrm{H}} \times H B F$ where $G_{\mathrm{H}}$ represents the hepatic vein blood glucose concentration. Net hepatic glucose balance (NHGB) was determined both indirectly $\left(N H G B_{\text {ind }}\right)$ and directly $\left(N H G B_{\text {dir }}\right)$ as the difference between $L O A D_{\text {out }}$ and the indirectly or directly calculated $L O A D_{\text {in }}$, with positive values representing net output of glucose by the liver and negative values representing net liver glucose uptake. With the exception of Table VI, all glucose balance and load data contained in the mean data base were calculated using the indirect approach.

Hepatic fractional extraction of glucose was calculated using the indirectly calculated $L O A D_{\text {in }}$ according to the following formula: extraction $\left.=\left[L O A D_{\text {in }}-L O A D_{\text {out }}\right) / L O A D_{\text {in }}\right] \times 100$.

Net hepatic lactate balance (NHLB) was calculated using the equation NHLB $=\left\{\left(L_{\mathrm{H}} \times H B F\right)-\left[\left(L_{\mathrm{A}} \times A B F\right) \pm\left(L_{\mathrm{P}} \times P B F\right)\right]\right\}$ where $L_{\mathrm{H}}$, $L_{\mathrm{A}}$, and $L_{\mathrm{P}}$ are the blood concentrations of lactate in the hepatic vein, artery, and portal vein, respectively. As with NHGB, calculation of NHLB in this manner gives positive values for net lactate output by the liver and negative values for net hepatic lactate uptake. Multiplication of NHLB by $0.09 \mathrm{mg}$ glucose/ $\mu \mathrm{mol}$ lactate was used to convert NHLB to glucose equivalents. Net hepatic balance of glucose equivalents was calculated as the sum of NHLB and NHGB $_{\text {ind }}$.

Hepatic fractional extraction of insulin was calculated according to the equation: $\left\{\left[\left(I_{\mathrm{A}} \times A P F\right)+\left(I_{\mathrm{P}} \times P P F\right)\right]-\left(I_{\mathrm{H}} \times H P F\right)\right\} /\left[\left(I_{\mathrm{A}} \times A P F\right)\right.$ $\left.+\left(I_{\mathrm{P}} \times P P F\right)\right]$ where $I_{\mathrm{A}}, I_{\mathrm{P}}$, and $I_{\mathrm{H}}$ represent insulin concentrations in the artery, portal vein, and hepatic vein, respectively, and $A P F, P P F$, and $H P F$ represent arterial, portal, and total hepatic plasma flow.

The average concentration of a substance entering the liver $\left(S_{\text {ave }}\right.$; calculated for glucose, insulin, and glucagon) was determined as follows: $S_{\text {ave }}=\left[\left(S_{\mathrm{A}} \times A F\right)+\left(S_{\mathrm{P}} \times P F\right)\right] / H F$ where $S_{\mathrm{A}}$ and $S_{\mathrm{P}}$ are the concentrations of the substance in the artery and the portal vein, respectively and $A F, P F$, and $H F$ represent blood or plasma flows in the vessels.

Peripheral (nonhepatic) uptake of glucose (PUG) was calculated as the difference between the total glucose infusion rate $\left(G I R_{\mathrm{T}}\right)$ and $N H G B_{\text {ind }}$. Peripheral glucose clearance was calculated as the ratio between PUG and the arterial plasma glucose concentration.

The distribution of hepatic blood flow between the hepatic artery and the portal vein was assumed to be 28 and $72 \%$, respectively (31), so that $A B F=0.28 \times H B F$ and $P B F=0.72 \times H B F$.

Values represent the means \pm SEM of the average steady-state data. Statistical significance $(P<0.05)$ was determined using the Student's $t$-test (32).

\section{Results}

Hormone values and glucose infusion rates. The average (weighted portal and arterial) plasma insulin levels entering the liver were similar in both groups $(24 \pm 7,89 \pm 5,91 \pm 5$, and $94 \pm 6$ $\mu \mathrm{U} / \mathrm{ml}$ in periods I-IV of $P_{\mathrm{e}}$, respectively, and $22 \pm 4,94 \pm 8$, $92 \pm 7$, and $93 \pm 7 \mu \mathrm{U} / \mathrm{ml}$ in the corresponding periods of $P_{\mathrm{o}}$ ). The fractional extraction of insulin by the liver did not change significantly in any period of either protocol (Table I). The average plasma glucagon concentration entering the liver rose from $75 \pm 7 \mathrm{pg} / \mathrm{ml}$ in the control period of $P_{\mathrm{e}}$ to $114 \pm 6,105 \pm 6$, and $99 \pm 10 \mathrm{pg} / \mathrm{ml}$ in periods II-IV, respectively (Table II). In $P_{\mathrm{o}}$ it rose from $80 \pm 11 \mathrm{pg} / \mathrm{ml}$ in the control period to $104 \pm 13$, $97 \pm 9$, and $90 \pm 8 \mathrm{pg} / \mathrm{ml}$ in periods II-IV, respectively. The glucagon levels in corresponding periods between the two groups were not significantly different.

Blood glucoses, hepatic blood flows, and hepatic glucose loads. The peripheral, portal, and total glucose infusion rates used during the three test periods of protocols 1 and 2 are listed in Table III. Although the total glucose infusion rate was higher 
Table I. Plasma Insulin Concentrations in the Artery, Portal Vein, and Hepatic Vein and the Hepatic Fractional Extraction of Insulin

\begin{tabular}{llcccc}
\hline & & \multicolumn{3}{c}{ Insulin concentration } & \\
\cline { 3 - 5 } Protocol & Period & Artery & $\begin{array}{c}\text { Portal } \\
\text { vein }\end{array}$ & $\begin{array}{c}\text { Hepatic } \\
\text { vein }\end{array}$ & $\begin{array}{c}\text { Hepatic fractional } \\
\text { extraction of insulin }\end{array}$ \\
\hline & & & $\mu U / m l$ & & $\%$ \\
$1\left(P_{\mathrm{e}}\right)$ & I & $9 \pm 2$ & $31 \pm 9$ & $12 \pm 4$ & $50 \pm 3$ \\
& II & $31 \pm 1^{*}$ & $111 \pm 6$ & $37 \pm 3$ & $56 \pm 4$ \\
& III & $33 \pm 2$ & $113 \pm 6$ & $37 \pm 3$ & $58 \pm 3$ \\
& IV & $34 \pm 2$ & $117 \pm 8$ & $41 \pm 4$ & $54 \pm 4$ \\
$2\left(P_{\mathrm{o}}\right)$ & I & $10 \pm 2$ & $27 \pm 5$ & $10 \pm 2$ & $49 \pm 3$ \\
& II & $34 \pm 2^{*}$ & $117 \pm 11$ & $46 \pm 5$ & $49 \pm 5$ \\
& III & $36 \pm 2^{*}$ & $113 \pm 10$ & $44 \pm 2$ & $50 \pm 4$ \\
& IV & $39 \pm 3^{*}$ & $114 \pm 10$ & $45 \pm 2$ & $50 \pm 4$ \\
& & & & & \\
\hline
\end{tabular}

Measured during periods I-IV of protocols 1 and 2. Values are means $\pm \operatorname{SEM}\left(n=7, P_{\mathrm{e}} ; n=6, P_{\mathrm{o}}\right)$.

* Significantly different from the other two test period values $(P$ $<0.05$ ).

in $P_{\mathrm{o}}$ than $P_{\mathrm{e}}$, the differences between the two groups did not reach statistical significance.

The stepwise increase in the exogenous glucose infusion rate raised the arterial blood glucose levels from $131 \pm 5 \mathrm{mg} / \mathrm{dl}$ in period II of $P_{\mathrm{e}}$ to $166 \pm 4$ and $200 \pm 4 \mathrm{mg} / \mathrm{dl}$ in periods III and IV, respectively, and from $111 \pm 6 \mathrm{mg} / \mathrm{dl}$ in period II of $P_{\mathrm{o}}$ to $140 \pm 5$ and $181 \pm 5 \mathrm{mg} / \mathrm{dl}$ in the remaining two test periods (Fig. $1 a$ and $b$ ). The average concentrations of blood glucose entering the liver were similar between corresponding periods of the two groups $(129 \pm 5,163 \pm 4$, and $197 \pm 5 \mathrm{mg} / \mathrm{dl}$ in periods II-IV of $P_{\mathrm{e}}$ and $132 \pm 6,158 \pm 6$, and $195 \pm 7 \mathrm{mg} / \mathrm{dl}$ in the same periods of $P_{\mathrm{o}}$ ).

Although hepatic blood flow tended to rise during the experimental portion of both studies (Fig. $1 c$ ), the increase did not reach statistical significance. Differences in the flow values between the two groups were also not significant.

The hepatic glucose load was raised from $29.3 \pm 2.5 \mathrm{mg} / \mathrm{kg} /$ min in the control period of $P_{\mathrm{e}}$ to $50.5 \pm 5.9,76.5 \pm 10.0$, and $93.6 \pm 10.0 \mathrm{mg} / \mathrm{kg} / \mathrm{min}$ in periods II-IV, respectively, and from $32.4 \pm 1.1 \mathrm{mg} / \mathrm{kg} / \mathrm{min}$ in the control period of $P_{\mathrm{o}}$ to $52.5 \pm 4.5$, $70.4 \pm 5.6$, and $103.6 \pm 18.4 \mathrm{mg} / \mathrm{kg} / \mathrm{min}$ in the remaining three

Table II. Plasma Glucagon Concentrations in the Artery and Portal Vein

\begin{tabular}{llcccc}
\hline & & \multicolumn{5}{c}{ Glucagon concentration during period: } \\
\cline { 3 - 6 } Protocol & Location & I & II & III & IV \\
\hline \multirow{4}{*}{$1\left(P_{\mathrm{e}}\right)$} & Artery & $59 \pm 6$ & $72 \pm 8$ & $65 \pm 8$ & $68 \pm 6$ \\
& Portal Vein & $81 \pm 8$ & $130 \pm 6$ & $121 \pm 6$ & $112 \pm 11$ \\
$2\left(P_{\mathrm{o}}\right)$ & Artery & $54 \pm 7$ & $64 \pm 5$ & $60 \pm 4$ & $58 \pm 6$ \\
& Portal Vein & $90 \pm 1$ & $120 \pm 17$ & $112 \pm 12$ & $103 \pm 10$
\end{tabular}

Measured during periods I-IV of protocols 1 and 2. Values are means $\pm \operatorname{SEM}\left(n=7, P_{\mathrm{e}} ; n=6, P_{\mathrm{o}}\right)$.
Table III. Rates of Glucose Infusion into a Peripheral Vein and the Portal Vein and the Total Glucose Infusion Rates

\begin{tabular}{ccccc}
\hline Protocol & Period & Peripheral & Portal & Total \\
\hline $1\left(P_{e}\right)$ & I & None infused & None infused & None infused \\
& II & $7.52 \pm 1.28$ & None infused & $7.52 \pm 1.28$ \\
& III & $11.52 \pm 1.74$ & None infused & $11.52 \pm 1.74$ \\
& IV & $16.30 \pm 1.68$ & None infused & $16.30 \pm 1.68$ \\
$2\left(P_{\mathrm{o}}\right)$ & I & None infused & None infused & None infused \\
& II & None infused & $10.36 \pm 1.94$ & $10.36 \pm 1.94$ \\
& II & $4.55 \pm 1.18$ & $10.52 \pm 2.12$ & $15.07 \pm 3.13$ \\
& IV & $10.78 \pm 2.17$ & $10.54 \pm 2.14$ & $21.32 \pm 3.34$
\end{tabular}

Used in periods I-IV of protocols 1 and 2 . Values are means $\pm \operatorname{SEM}(n$ $=7, P_{\mathrm{e}} ; n=6, P_{\mathrm{o}}$ ).

periods (Fig. $2 a$ ). Differences between the two groups did not reach statistical significance.

Net hepatic glucose balance and hepatic fractional extraction of glucose. The liver switched from net production of glucose during the control period $(1.87 \pm 0.07$ and $1.90 \pm 0.21 \mathrm{mg} /$ $\mathrm{kg} / \mathrm{min}$, in $P_{\mathrm{e}}$ and $P_{\mathrm{o}}$, respectively) to net consumption of glucose in the remainder of the experiment (Fig. 2 b). Net hepatic glucose uptake rose in both groups as the load of glucose to the liver was raised $(1.16 \pm 0.37,2.78 \pm 0.82$, and $5.07 \pm 1.20 \mathrm{mg} / \mathrm{kg} /$ min in periods II-IV of $P_{\mathrm{e}}$ and $3.77 \pm 0.40,4.80 \pm 0.59$, and $9.62 \pm 1.43 \mathrm{mg} / \mathrm{kg} / \mathrm{min}$ in the corresponding periods of $P_{\mathrm{o}}$ ). Thus, infusion of glucose into the portal vein resulted in as much as a threefold increase in net uptake of glucose by the liver $\left(P<0.05 ; P_{\mathrm{o}}\right.$ vs. $\left.P_{\mathrm{e}}\right)$.

The dependence of net hepatic glucose uptake on hepatic glucose load in the presence of basal glucagon and three- to fourfold basal insulin levels is represented in Fig. $3 \mathrm{a}$. Although net hepatic glucose uptake increased in both protocols with increases in the hepatic glucose load, net uptake of glucose by the liver was greater at all points during intraportal glucose delivery $\left(P_{\mathrm{o}}\right)$. The impact of intraportal glucose delivery was greatest at the lowest, most physiological load examined. A similar type of relationship was evident between net hepatic glucose uptake and the load of glucose in the portal vein (Fig. $3 b$ ).

Hepatic fractional extraction of glucose increased with the increment in the hepatic glucose load from $2.44 \pm 0.80 \%$ to $3.87 \pm 1.09 \%$ and finally to $6.01 \pm 1.59 \%$ in the three experimental periods of $P_{e}($ all $P<0.05)$ and from $7.41 \pm 0.92$ and $7.06 \pm 0.10 \%$ in periods II and III, respectively, of $P_{\mathrm{o}}$ to $9.66 \pm 0.76 \%$ at the highest load studied $(P<0.05)$. Although hepatic fractional extraction of glucose in $P_{\mathrm{e}}$ approached that observed in $P_{\mathrm{o}}$, the values were never the same even at the highest glucose load examined $(P<0.05$; Fig. 4$)$.

Lactate concentrations, hepatic lactate metabolism, and net hepatic uptake of glucose equivalents. Arterial blood lactate levels rose in a similar manner throughout the study in both protocols (Table IV). The liver switched from net consumption of lactate during the control period of $P_{e}(8.42 \pm 1.32 \mu \mathrm{mol} / \mathrm{kg} /$ $\mathrm{min})$ to net production of lactate in the remaining three periods $(3.59 \pm 1.47,6.38 \pm 5.12$, and $13.12 \pm 6.32 \mu \mathrm{mol} / \mathrm{kg} / \mathrm{min}$ during periods II-IV of $P_{\mathrm{e}}$, respectively). The pattern was similar in $P_{\mathrm{o}}$ with the liver consuming $9.59 \pm 1.62 \mu \mathrm{mol} / \mathrm{kg} / \mathrm{min}$ of lactate during the control period, producing a small amount of lactate 
Protocol 1 (Pe)

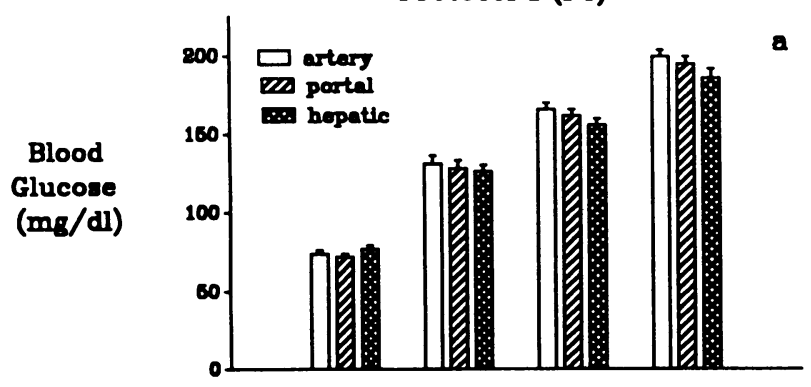

Protocol 2 (Po)

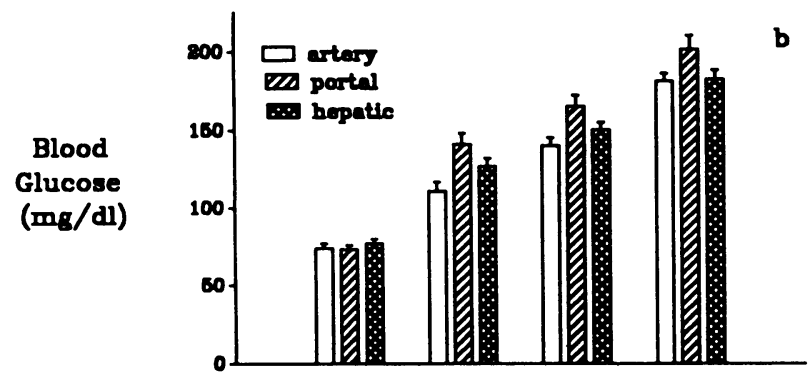

HBF (ml/kg/min)

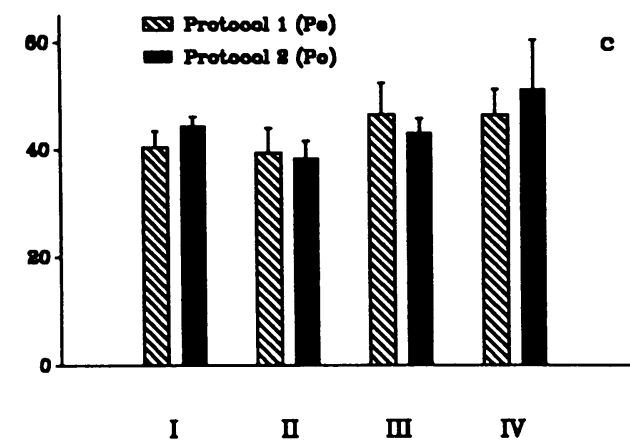

Figure 1. Blood glucose levels $(\mathrm{mg} / \mathrm{dl})$ in the artery, portal vein, and hepatic vein as well as total hepatic blood flow (HBF; $\mathrm{ml} / \mathrm{kg} / \mathrm{min}$ ) during glucose infusion in the presence of somatostatin, basal intraportal glucagon, and fourfold basal intraportal insulin in conscious 42-h fasted dogs. In protocol $2\left(P_{\mathrm{o}}\right)$, a portion of the glucose was infused intraportally so as to provide the "portal" signal. Values are means $\pm \operatorname{SEM}\left(n=7, P_{\mathrm{e}} ; n=6, P_{\mathrm{o}}\right)$.

in period II $(1.05 \pm 3.38 \mu \mathrm{mol} / \mathrm{kg} / \mathrm{min})$, consuming a small amount of lactate in period III $(0.51 \pm 3.96 \mu \mathrm{mol} / \mathrm{kg} / \mathrm{min})$, and then producing some in period IV $(8.15 \pm 4.39 \mathrm{Immol} / \mathrm{kg} / \mathrm{min})$. The differences between values in the corresponding periods of the two groups were not significant. Net hepatic balance of glucose equivalents demonstrated a dose dependence on the hepatic glucose load similar to that of the net hepatic glucose balance, which, was significantly altered in the presence of intraportal glucose delivery (Fig. 5).

Peripheral glucose uptake and clearance. Peripheral (nonhepatic) glucose uptake and clearances for the entire data base (unpaired) and for only the five dogs on which both protocols were performed (paired) are listed in Table V. Peripheral glucose uptake increased in parallel with the increase in the arterial plasma glucose level in all groups and did not differ significantly between corresponding periods of the two protocols. Since the arterial glucose level was slightly different in the $P_{\mathrm{e}}$ and $P_{\mathrm{o}}$ studies, the peripheral glucose clearance rate was calculated to normalize the peripheral glucose uptake data in order to facilitate direct comparison of the results from the two groups. As expected, insulin infusion increased peripheral glucose clearance in both protocols. Even though $P_{\mathrm{o}}$ values from the unpaired data appeared to be greater than $P_{\mathrm{e}}$ values, the differences between the corresponding values in the two groups were not significant. In addition, the similarity between the two groups is even more evident when paired data are used to support this. Thus, under the present conditions, intraportal glucose delivery had no detectable peripheral effects.

\section{Discussion}

Although many studies support the assumption that the load of glucose reaching the liver plays a major role in the regulation of liver glucose uptake $(2-8,15)$, the precise relationship between the two variables, and the influence of the route of glucose delivery on this relationship, have yet to be defined in vivo. The results of the present experiments indicate that there is an approximately linear relationship between the hepatic glucose load and net hepatic glucose uptake over the range of glucose loads used. In addition, delivery of a portion of
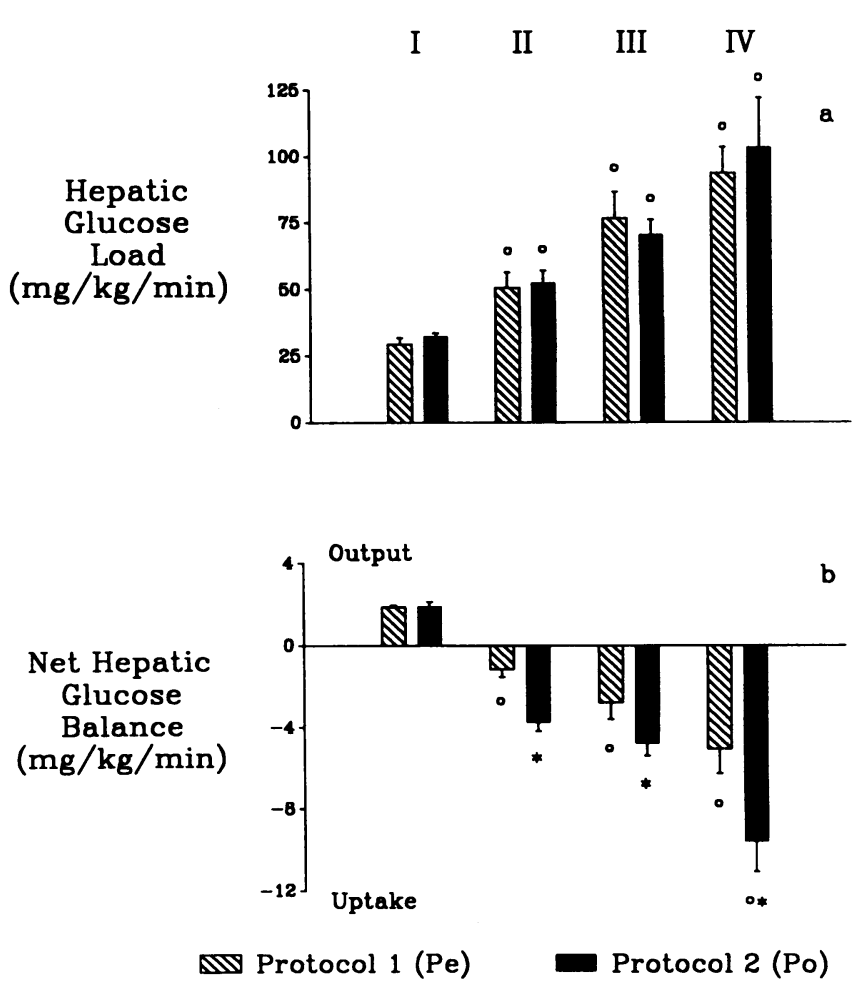

Figure 2. Hepatic glucose loads and net hepatic glucose balances $(\mathrm{mg} / \mathrm{kg} / \mathrm{min})$ during periods I-IV of protocols 1 and 2 . Values are means \pm SEM $\left(n=7, P_{c} ; n=6, P_{\mathrm{o}}\right)$. $\left({ }^{*}\right)$ Significantly different from value in corresponding period of $P_{\mathrm{e}}(P<0.05)$. $\left(^{\circ}\right)$ Significantly different from the other two test period values $(P<0.05)$. 

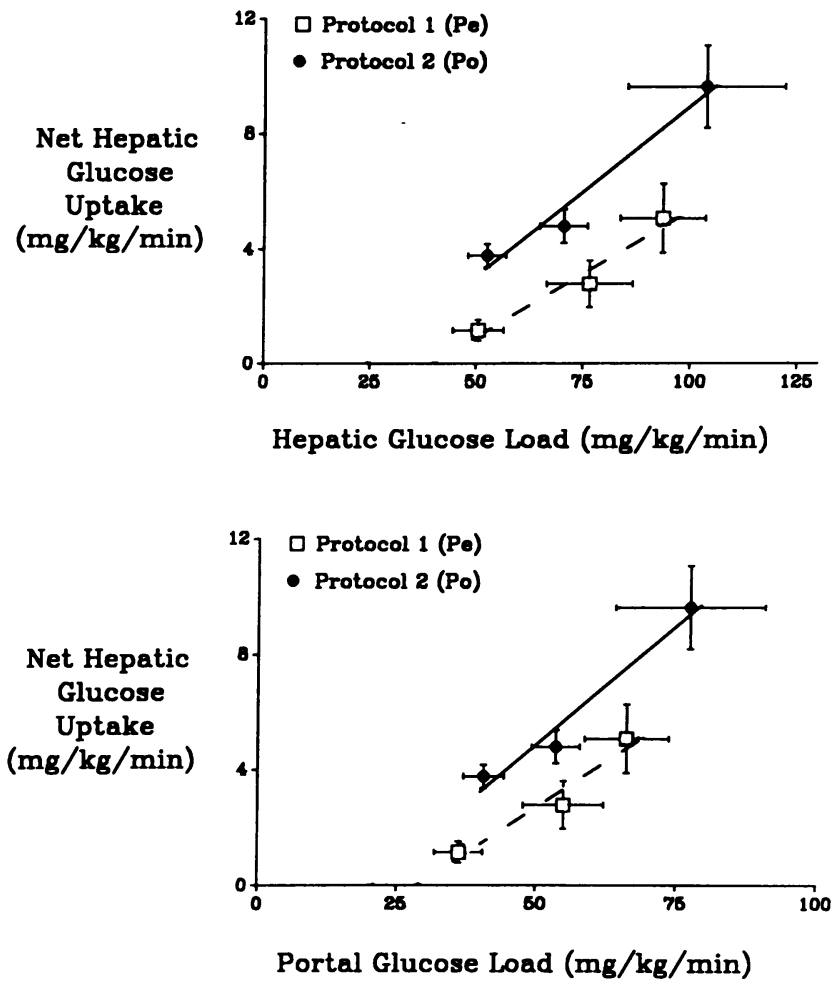

Figure 3. Relationship between net uptake of glucose by the liver $(\mathrm{mg} / \mathrm{kg} / \mathrm{min})$ and the hepatic or portal glucose loads $(\mathrm{mg} / \mathrm{kg} / \mathrm{min})$ during glucose infusion in the presence of somatostatin, basal intraportal glucagon, and fourfold basal intraportal insulin in conscious 42-h fasted dogs. In protocol $2\left(P_{\mathrm{o}}\right)$ a portion of the glucose was infused intraportally so as to provide the "portal" signal. Values are means $\pm \operatorname{SEM}\left(n=7, P_{\mathrm{e}} ; n=6, P_{\mathrm{o}}\right)$.

the exogenous glucose load directly into the portal vein increased net hepatic glucose uptake by two- to threefold even when care was taken to maintain comparable insulin, glucagon, and glucose loads to the liver.

Although the present results clearly demonstrate the impor-

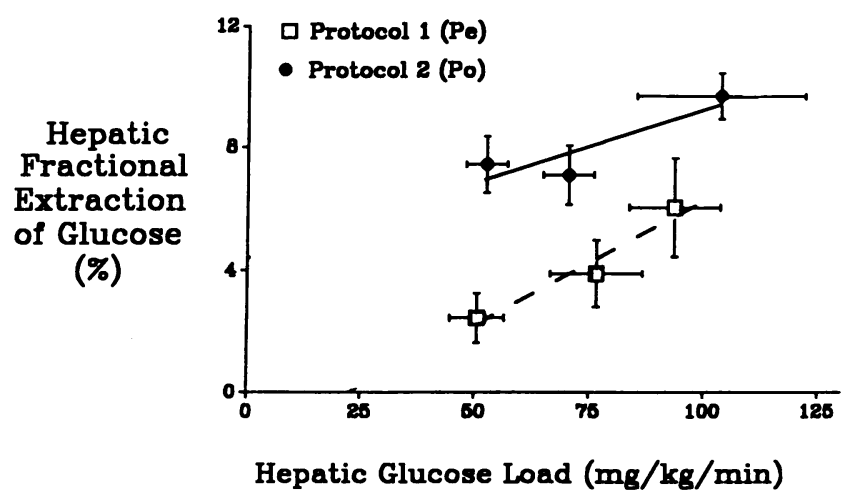

Figure 4. Relationship between hepatic fractional extraction of glucose (\%) and the hepatic glucose load $(\mathrm{mg} / \mathrm{kg} / \mathrm{min})$ during glucose infusion in the presence of somatostatin, basal intraportal glucagon, and fourfold basal intraportal insulin in conscious 42-h fasted dogs. In protocol $2\left(P_{0}\right)$ a portion of the glucose was infused intraportally so as to provide the "portal" signal. Values are means $\pm \operatorname{SEM}\left(n=7, P_{e}\right.$; $n=6, P_{\mathrm{o}}$ ).

Table IV. Lactate Concentrations in the Artery, Portal Vein and Hepatic Vein and the Net Hepatic Lactate Balance

\begin{tabular}{llcccr}
\hline & & \multicolumn{3}{c}{ Concentration } & $\begin{array}{c}\text { Net hepatic } \\
\text { Protocol }\end{array}$ \\
\cline { 3 - 6 } & Period & Artery & Portal & Hepatic & latte balance \\
\hline & & & $m M$ & & $\mu \mathrm{mol} / \mathrm{kg} / \mathrm{min}$ \\
$1\left(P_{\mathrm{e}}\right)$ & I & $0.36 \pm 0.05$ & $0.44 \pm 0.06$ & $0.21 \pm 0.05$ & $-8.42 \pm 1.32$ \\
& II & $0.77 \pm 0.11$ & $0.77 \pm 0.10$ & $0.87 \pm 0.15$ & $3.59 \pm 1.47$ \\
& III & $1.09 \pm 0.13$ & $1.08 \pm 0.13$ & $1.23 \pm 0.21$ & $6.38 \pm 5.12$ \\
& IV & $1.33 \pm 0.17$ & $1.28 \pm 0.16$ & $1.58 \pm 0.28$ & $13.12 \pm 6.32$ \\
$2\left(P_{\mathrm{o}}\right)$ & I & $0.44 \pm 0.07$ & $0.50 \pm 0.07$ & $0.27 \pm 0.06$ & $-9.59 \pm 1.62$ \\
& II & $0.91 \pm 0.12$ & $0.90 \pm 0.12$ & $0.95 \pm 0.13$ & $1.05 \pm 3.38$ \\
& III & $1.28 \pm 0.11$ & $1.20 \pm 0.10$ & $1.22 \pm 0.09$ & $-0.51 \pm 3.96$ \\
& IV & $1.51 \pm 0.14$ & $1.39 \pm 0.14$ & $1.60 \pm 0.14$ & $8.15 \pm 4.39 *$
\end{tabular}

During periods I-IV of protocols 1 and 2 . Values are means $\pm \operatorname{SEM}(n$ $=7, P_{\mathrm{e}} ; n=6, P_{\mathrm{o}}$ )

* Significantly different from the other two test period values $(P$ $<0.05)$.

tance of the route of glucose delivery in determining the magnitude of net hepatic glucose uptake, the shape of the dose-response curve (Fig. 3) suggests that the effects of intraportal glucose delivery on NHGU may be most dramatic at smaller glucose loads. Indeed, it appears that with a load of glucose not high enough to trigger net hepatic glucose uptake when the glucose is delivered peripherally, the liver takes up as much as $1.9 \mathrm{mg} / \mathrm{kg} / \mathrm{min}$ when the same hepatic glucose load has resulted from intraportal glucose delivery. Thus, it would appear that with moderate excursions in the blood sugar level the liver is able to take up significant amounts of glucose only if the glucose load has been delivered intraportally.

The two- to threefold increase in net hepatic glucose uptake caused by intraportal glucose delivery in these studies is less than the almost sixfold increase in net splanchnic glucose uptake observed by DeFronzo et al. (17) in response to oral glucose administration in man, and by Ishida et al. (19) during intraportal glucose administration in dog. The greater rises in plasma insulin values and the large decline in plasma glucagon levels occurring in the studies by DeFronzo et al. (17) and

Net Hepatic Balance
in Glucose Equivalents
(Glucose + Lactate)
(mg/kg/min)

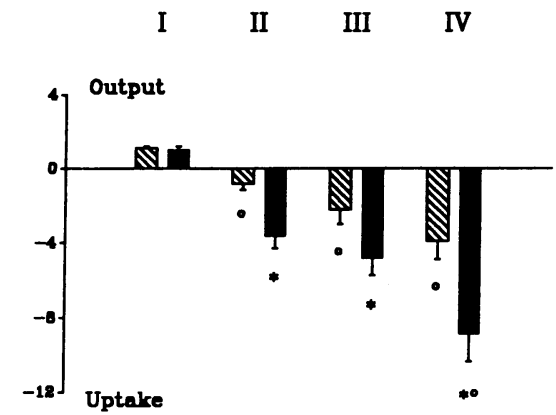

NTV Protocol 1 (Pe)

Protocol 2 (Po)

Figure 5. Net balance of glucose equivalents (glucose and lactate) across the liver $(\mathrm{mg} / \mathrm{kg} / \mathrm{min})$ during periods I-IV of protocols 1 and 2. Values are means $\pm \operatorname{SEM}\left(n=7, P_{\mathrm{e}} ; n=6, P_{\mathrm{o}}\right)$. $\left(^{*}\right)$ Significantly different from corresponding period of $P_{\mathrm{e}}(P<0.05)$. $\left({ }^{\circ}\right)$ Significantly different from the other two test period values $(P<0.05)$. 
Table V. Peripheral (Nonhepatic) Glucose Uptake and Peripheral (Nonhepatic) Glucose Clearance

\begin{tabular}{llccccc}
\hline & & \multicolumn{2}{c}{ Peripheral glucose uptake } & & \multicolumn{2}{c}{ Peripheral glucose clearance } \\
\cline { 3 - 4 } \cline { 6 - 7 } Protocol & Period & Paired & Unpaired & & Paired & Unpaired \\
\hline $1\left(P_{\mathrm{e}}\right)$ & I & $1.93 \pm 0.08$ & $1.87 \pm 0.07$ & & $1.86 \pm 0.08$ & $1.78 \pm 0.08$ \\
& II & $7.34 \pm 1.99^{\ddagger}$ & $6.37 \pm 1.54^{\ddagger}$ & & $3.82 \pm 1.05$ & $3.35 \pm 0.79$ \\
& III & $10.03 \pm 3.02^{\ddagger}$ & $8.75 \pm 2.24^{\ddagger}$ & & $4.23 \pm 1.22$ & $3.66 \pm 0.92$ \\
& IV & $12.78 \pm 3.75^{\ddagger}$ & $11.23 \pm 2.74^{\ddagger}$ & & $4.18 \pm 1.12$ & $3.68 \pm 0.83$ \\
$2\left(P_{\mathrm{o}}\right)$ & I & $1.84 \pm 0.26$ & $1.90 \pm 0.21$ & & $1.76 \pm 0.23$ & $1.82 \pm 0.19$ \\
& II & $5.90 \pm 2.26^{* \ddagger}$ & $6.59 \pm 1.96^{\ddagger}$ & & $4.04 \pm 1.83$ & $4.56 \pm 1.57$ \\
& III & $9.47 \pm 3.42$ & $10.27 \pm 2.88$ & & $4.93 \pm 1.82$ & $5.42 \pm 1.56$ \\
& IV & $9.84 \pm 2.74$ & $11.69 \pm 2.98$ & & $3.89 \pm 1.11$ & $4.58 \pm 1.16$
\end{tabular}

Periods I-IV of Protocols 1 and 2 (Paired: $n=5$; Unpaired: $n=7, P_{\mathrm{e}}$; $n=6, P_{\mathrm{o}}$ ).

* Significantly different from corresponding period of $P_{\mathrm{e}}(P<0.05)$.

${ }^{\ddagger}$ Significantly different from other two test period values $(P<0.05)$.

Ishida et al. (19), the less accurate matching of hepatic glucose and insulin loads between the oral and the peripheral glucose administration periods in the studies by DeFronzo et al. (17), and the use of plasma glucose instead of blood glucose values in the determination of net glucose uptake may all have contributed to this difference. Despite these discrepancies, the increase in uptake observed in the present experiments is comparable to the 2.5 -fold increase reported by Adkins et al. $(16,21)$ in the $\mathrm{dog}$ as a result of intraportal glucose administration, and demonstrates unequivocally the importance of the route of glucose delivery in the determination of net hepatic glucose uptake.

The lack of saturation of hepatic glucose uptake evident with either route of glucose delivery, though predictable from the results of in vitro experiments (the $K_{\mathrm{m}}$ of the liver glucose transporter [Glut 2] is $20 \mathrm{mM}$ ) is noteworthy and presumably reflects the liver's great capacity as a glucose storage organ (33). The increase in NHGU and the lack of saturation of the process were likely due to a combination of a mass-action effect of glucose and an effect of glucose on hepatic enzymes. Demonstrations in in vitro systems that glucose administration in either the absence or the presence of insulin causes an activation of glycogen synthase and an inactivation of glycogen phosphorylase (34-36) strongly suggest that at least part of the increase in glucose uptake observed in the present experiments was caused by a direct action of glucose on the enzymes involved in glycogen metabolism. Indeed, only the direct effects of glucose on the glycogen enzyme system and not the possible mass-action effects of glucose can explain the increase in the rate of hepatic glycogen synthesis and total glycogen levels observed after the administration of a glucose load in rats when both hepatic glucose-6-phosphate and UDP-glucose concentrations had decreased $(34,37)$.

Although the fractional extraction of glucose by the liver is often presumed to be constant over a wide range of glucose levels, the present results indicate that hepatic fractional extraction of glucose is influenced by the hepatic glucose load particularly if no portion of the glucose load has entered via the portal vein; therefore, use of this parameter to compare liver glucose uptake at greatly dissimilar glucose loads should be interpreted with caution.
The average concentration of insulin reaching the liver and the fractional extraction of insulin by the liver were similar in the two protocols and corresponded to values in the literature $(38-41)$. Thus insulin per se can be eliminated as a possible factor contributing to the difference observed in the hepatic response to peripheral and intraportal glucose delivery. Infusion of glucagon at $0.65 \mathrm{ng} / \mathrm{kg} / \mathrm{min}$, though meant to replace basal pancreatic glucagon secretion, resulted in a slight rise in glucagon in both groups, suggesting that endogenous glucagon secretion was slightly below the rate at which the hormone was infused. The gradual drop in the average concentration of glucagon entering the liver in both protocols was most likely of little or no significance, due to the presence of combined hyperinsulinemia and hyperglycemia (42). In addition, the similarity of the glucagon values between the two groups indicates that the differences in hepatic glucose uptake observed between peripheral and intraportal glucose infusion could not be due to differences in glucagon levels.

Because technical problems associated with the infusion of a substance directly into the portal vein could have had a major impact on the results of these studies, great care was taken to examine and eliminate potential technical errors wherever possible. Adequate mixing of the intraportal glucose infusate with the blood perfusing the liver was of great concern, for systematic errors in mixing, while not affecting NHGU calculated during peripheral glucose delivery, could have caused errors in the calculation of NHGU during intraportal glucose delivery. The excellent hepatic recovery of PAH in these experiments $(93 \pm 6 \%)$ indicates that improper mixing was not a major problem, and when good mixing did not occur, the error was random so that the mean data still gave an accurate representation of the liver's response.

To circumvent the use of the portal glucose value in the calculation of NHGB and thus further decrease possible errors due to poor mixing, an "indirect" method of calculating net hepatic glucose balance was used as described previously (16, 21). Comparison of this indirect method and the more commonly used direct method of calculation of NHGB (Table VI) shows that the absolute values obtained from the two approaches were not significantly different. The conclusions drawn regarding both the dose-response curve and the "portal" signal were unaffected by the method of calculation chosen.

The simplest way to calculate NHGB is to multiply the

Table VI. Comparison of Direct and Indirect Calculations of Net Hepatic Glucose Balance

\begin{tabular}{|c|c|c|c|}
\hline Protocol & Period & Direct & Indirect \\
\hline \multirow[t]{4}{*}{$1\left(P_{e}\right)$} & I & $1.87 \pm 0.07$ & $1.87 \pm 0.07$ \\
\hline & II & $-1.07 \pm 0.38^{* \pm}$ & $-1.16 \pm 0.37^{* \pm}$ \\
\hline & III & $-2.61 \pm 0.76^{* \ddagger}$ & $-2.78 \pm 0.82^{* \pm}$ \\
\hline & IV & $-4.37 \pm 1.25^{* \ddagger}$ & $-5.07 \pm 1.20^{* \pm}$ \\
\hline \multirow[t]{4}{*}{$2\left(P_{0}\right)$} & I & $1.90 \pm 0.21$ & $1.90 \pm 0.21$ \\
\hline & II & $-2.61 \pm 0.68^{* \pm}$ & $-3.77 \pm 0.40^{*}$ \\
\hline & III & $-5.32 \pm 0.82^{* \pm}$ & $-4.80 \pm 0.59^{*}$ \\
\hline & IV & $-8.00 \pm 1.08^{* \pm}$ & $-9.62 \pm 1.43^{* \neq}$ \\
\hline
\end{tabular}

Values are means $\pm \operatorname{SEM}\left(n=7, P_{e} ; n=6, P_{\mathrm{o}}\right)$.

* Significantly different from corresponding period of $P_{\mathrm{e}}(P<0.05)$.

¥ Significantly different from other two test period values $(P<0.05)$. 
whole blood glucose difference across the liver by the hepatic blood flow. Given the need to deproteinize the blood sample and the analytical error in measuring glucose on the autoanalyzer, we attempted to additionally calculate NHGB using HBF and plasma glucose values corrected to whole blood glucose values using blood/plasma glucose ratios determined in each experiment. Table VII shows that in fact this difference in approach had little effect on the data obtained and made no difference to the conclusions drawn regarding glucose's ability to stimulate glucose uptake by the liver or the ability of the "portal" signal to trigger additional hepatic glucose uptake.

Use of the dye extraction technique for blood flow estimation introduced a second potential source of technical error. Although a simple, accurate method of assessing hepatic blood flow, this technique measures only total hepatic blood flow, so that a percent distribution of flow between the hepatic artery and the portal vein must be assumed. In a separate set of experiments (43) in which hepatic blood flow was determined using the synchronized, pulsed Doppler method, a method providing direct measurements of hepatic artery and portal vein flow during hyperglycemia and hyperinsulinemia, the average flow distribution measured was $75 \%$ portal $/ 25 \%$ hepatic artery. Results from the present study calculated using the above flow distribution, or the $80 \%$ portal $/ 20 \%$ artery distribution reported by Ishida et al. (19), resulted in only a slight change in net hepatic glucose balance calculated using the indirect method $(75 / 25$ : $-1.13,-2.74$, and $-5.03 \mathrm{mg} / \mathrm{kg} / \mathrm{min}$ in periods II-IV of $P_{\mathrm{e}}$ vs. $-3.75,-4.77$, and $-9.58 \mathrm{mg} / \mathrm{kg} / \mathrm{min}$ in II-IV of $P_{\mathrm{o}} ; 80 / 20$ : $-1.08,-2.68$, and $-4.95 \mathrm{mg} / \mathrm{kg} / \mathrm{min}$ in II-IV of $P_{e}$, and -3.72 , -4.73 , and -9.44 in II-IV of $P_{\mathrm{o}}$ ), and actually caused an accentuation in the difference between the two routes of glucose delivery when the direct method of calculation was used (75/ 25: $-1.03,-2.57$, and $-4.30 \mathrm{mg} / \mathrm{kg} / \mathrm{min}$ in periods II-IV of $P_{\mathrm{e}}$ vs. $-2.85,-5.62$, and $-8.20 \mathrm{mg} / \mathrm{kg} / \mathrm{min}$ in II-IV of $P_{\mathrm{o}} ; 80 / 20$ : $-0.98,-2.49$, and $-4.18 \mathrm{mg} / \mathrm{kg} / \mathrm{min}$ in II-IV of $P_{\mathrm{e}}$ and -3.26 , -6.12 , and $-8.60 \mathrm{mg} / \mathrm{kg} / \mathrm{min}$ in II-IV of $P_{\mathrm{o}}$ ).

Consistent with the findings of Shulman et al. (44), increasing the blood glucose level resulted in a dose-dependent rise in blood lactate levels and a change in the hepatic lactate balance from one of lactate uptake to one of lactate output. Even though net lactate production was occurring, the amount of

Table VII. Comparison of Net Hepatic Glucose Balance Calculated Using Whole Blood Glucose or Plasma Glucose Converted to Whole Blood Glucose

\begin{tabular}{llcc}
\hline Protocol & Period & $\begin{array}{c}\text { Whole blood } \\
\text { glucose }\end{array}$ & $\begin{array}{c}\text { Plasma converted to } \\
\text { blood glucose }\end{array}$ \\
\hline $1\left(P_{\mathrm{e}}\right)$ & I & $1.85 \pm 0.19$ & $1.87 \pm 0.07$ \\
& II & $-0.71 \pm 0.43^{* \ddagger}$ & $-1.16 \pm 0.36^{* \neq}$ \\
& III & $-2.93 \pm 0.61^{* \ddagger}$ & $-2.78 \pm 0.82^{* \neq}$ \\
& IV & $-4.51 \pm 0.94^{* \ddagger}$ & $-5.07 \pm 1.20^{* \neq}$ \\
$2\left(P_{\mathrm{o}}\right)$ & I & $1.92 \pm 0.18$ & $1.90 \pm 0.21$ \\
& II & $-3.53 \pm 0.43^{* \ddagger}$ & $-3.77 \pm 0.40^{*}$ \\
& III & $-4.90 \pm 0.57^{* \neq}$ & $-4.80 \pm 0.59^{*}$ \\
& IV & $-9.30 \pm 1.50^{* \neq}$ & $-9.62 \pm 1.43^{* \ddagger}$ \\
\hline
\end{tabular}

Values are mean $\pm \operatorname{SEM}\left(n=7, P_{e} ; n=6, P_{\mathrm{o}}\right)$.

* Significantly different from corresponding period of $P_{\mathrm{e}}(P<0.05)$.

${ }^{\ddagger}$ Significantly different from other two test period values $(P<0.05)$. glucose represented by the lactate leaving the liver was small compared with the total amount of glucose taken up by the liver. This, together with the similarity of net hepatic lactate production during peripheral and intraportal glucose delivery, suggests that the fate of the extra glucose taken up by the liver during portal glucose delivery was either hepatic glucose storage or oxidation and not simply increased glycolysis.

Since intraportal glucose delivery may also alter peripheral glucose uptake (15), the effect of intraportal glucose delivery on peripheral glucose metabolism was examined. Although peripheral glucose clearance tended to be less during peripheral glucose delivery, differences between the two groups were not statistically significant and were eliminated when paired data were examined. Differences between the results of the present study and those of Adkins et al. (21) were most likely due to differences in insulin levels. In a recent publication by Myers et al. (43), the effect of intraportal glucose delivery on peripheral glucose metabolism was evaluated at three different arterial insulin concentrations $(18,36$, and $90 \mu \mathrm{U} / \mathrm{ml})$. As in this study, no effect of the route of glucose delivery on peripheral glucose uptake was evident at the middle or high dose of insulin, but a significant lowering of both peripheral glucose uptake and peripheral glucose clearance was observed at the lowest concentration of insulin studied, levels much closer to those used in the study by Adkins et al. (21).

Although the importance of the role of intraportal glucose delivery in the regulation of net hepatic glucose uptake has been demonstrated by this and other studies $(16-21,44,45)$, the mechanism by which intraportal glucose delivery increases hepatic glucose uptake has not yet been defined. One possible explanation involves the difference in the anatomical distribution of the glucose load to the liver during the two routes of glucose administration. For the same average concentration of glucose entering the liver, the portal vein glucose level is higher during intraportal glucose delivery than it is during a purely peripheral glucose infusion. It is possible that the hepatocytes perfused mainly or exclusively by portal vein blood (presumably the majority of the hepatocytes since the majority of blood perfusing the liver, $\sim 72 \%$, enters via the portal vein) could be responding to the larger load of glucose in the portal vein by increasing their rates of glucose uptake, resulting in a greater net uptake of glucose by the liver during intraportal glucose delivery. If this were correct, at comparable portal vein glucose loads, net hepatic glucose uptake during intraportal glucose delivery should be the same or less than that during peripheral glucose administration. It is evident from Fig. 4 that this is not the case. Thus, results from the present experiments indicate that the difference in the liver's response to peripheral and intraportal glucose delivery cannot be due merely to differences in portal vein glucose levels.

It is now apparent that a "gut" factor as proposed by DeFronzo et al. (17), is probably not involved $(19,20,22,46)$ in the augmentation of hepatic glucose uptake that occurs following oral glucose since it occurred in the presence of portal glucose delivery when the gut was bypassed. The arterial-portal glucose gradient is the parameter most obviously different between the two glucose delivery routes. It seems possible that this gradient creates a signal that then triggers the response. Indeed, a recent study Pagliassotti et al. (47) reported a sensitive relationship between the magnitude of the negative arterial portal glucose gradient and NHGU. The nature of this "portal" signal is not yet known, although indirect evidence for a neural 
mechanism is impressive. Reports from several different investigators (48-56) support the idea that the parasympathetic nervous system may be playing an important role. In addition, in a preliminary report from this laboratory (57), it was noted that a nearly complete denervation of the liver caused the loss of the effects of intraportal glucose delivery in the dog, suggesting that the effects of intraportal glucose delivery are neurally mediated. Still, as with the fate of glucose removed by the liver, further investigation is needed to determine the exact mechanism by which intraportal glucose delivery exerts its effects.

In summary, in the present experiments net hepatic glucose uptake demonstrated a direct dependence on the hepatic glucose load that did not reach saturation even at elevations in the hepatic glucose load of greater than three times basal. In addition, the presence of intraportal glucose delivery increased net hepatic glucose uptake apparently by lowering the threshold at which the liver switched from net glucose output to net glucose uptake. Changes in hepatic lactate metabolism could not account for the changes in hepatic glucose uptake observed, suggesting that an alteration in hepatic glycogen metabolism may be involved.

\section{Acknowledgments}

We gratefully acknowledge the excellent technical assistance of $\mathbf{R}$. Keith Carr and secretarial assistance of Patsy Raymer and the advice of Dr. M. Pagliassotti.

This work was supported by National Institutes of Health grant R01-AM-18243-12 and Diabetes Research and Training Center NIH grant P60 DK-20593-10.

\section{References}

1. Bernard, C. 1877. Leçons sur le diabéte. J. B. Baillière, Paris

2. Bucolo, R. J., R. N. Bergman, D. J. Marsh, and F. E. Yates. 1974. Dynamics of glucose autoregulation in the isolated, blood-perfused canine liver. Am. J. Physiol. 227:209-217.

3. Cahill, G. F., A. B. Hastings, J. Ashmore, and S. Zottu. 1958. Studies on carbohydrate metabolism in rat liver slices. X. Factors in the regulation of pathways of glucose metabolism. J. Biol. Chem. 230:125-135.

4. Davidson, M. B. 1981 . Autoregulation by glucose of hepatic glucose balance: permissive effect of insulin. Metabolism. 30:279-284.

5. Glinsmann, W. H., E. P. Hern, and A. Lynch. 1969. Intrinsic regulation of glucose output by rat liver. Am. J. Physiol. 216:698-703.

6. Witters, L. A., and J. Avruch. 1978. Insulin regulation of hepatic glycogen synthase and phosphorylase. Biochemistry. 17:406-410.

7. Soskin, S., H. E. Essex, J. F. Herrick, and F. C. Mann. 1938. The mechanism of regulation of the blood sugar by the liver. Am. J. Physiol. 124:558-567.

8. Shoemaker, W. C., H. M. Yanof, L. N. Turk, and T. H. Wilson. 1963. Glucose and fructose absorption in the unanesthetized dog. Gastroenterology. 44:654-663.

9. Saccà, L., R. Hendler, and R. S. Sherwin. 1978. Hyperglycemia inhibits glucose production in man independent of changes in glucoregulatory hormones J. Clin. Endocrin. Metab. 47:1160-1163.

10. Shulman, G. I., J. E. Liljenquist, P. E. Williams, W. W. Lacy, and A. D. Cherrington. 1978. Glucose disposal during insulinopenia in somatostatintreated dogs: the roles of glucose and glucagon. J. Clin. Invest. 62:487-491.

11. Liljenquist, J. E., G. L. Mueller, A. D. Cherrington, J. M. Perry, and D. Rabinowitz. 1979. Hyperglycemia per se (insulin and glucagon withdrawn) can inhibit hepatic glucose production in man. J. Clin. Endocrin. \& Metab. 48:171175.

12. Saccà, L., D. Vitale, M. Cicala, B. Trimarco, and B. Ungaro. 1981. The glucoregulatory response to intravenous glucose infusion in normal man: Roles of insulin and glucose. Metabolism. 30:457-461.

13. Saccà, L., M. Cicala, B. Trimarco, B. Ungaro, and C. Vigorito. 1982 Differential effects of insulin on splanchnic and peripheral glucose disposal after an intravenous glucose load in man. J. Clin. Invest. 70:117-126.

14. Cherrington, A. D., P. E. Williams, N. Abou-mourad, W. W. Lacy, K. E Steiner, and J. E. Liljenquist. 1982. Insulin as a mediator of hepatic glucose uptake in the conscious dog. Am. J. Physiol. 242:E97-E101.
15. DeFronzo, R. A., E. Ferrannini, R. Hendler, P. Felig, and F. Wahren. 1983. Regulation of splanchnic and peripheral glucose uptake by insulin and hyperglycemia in man. Diabetes. 32:35-45.

16. Adkins, B. A., S. R. Myers, G. K. Hendrick, R. W. Stevenson, P. E Williams, and A. D. Cherrington. 1987. Importance of the route of intravenous glucose delivery to hepatic glucose balance in the conscious dog. J. Clin. Invest. 79:557-565.

17. DeFronzo, R. A., E. Ferrannini, R. Hendler, J. Wahren, and P. Felig. 1978. Influence of hyperinsulinemia, hyperglycemia, and the route of glucose administration on splanchnic glucose exchange. Proc. Natl. Acad. Sci. USA. 75:5173-5177.

18. Ferrannini, E., J. Wahren, P. Felig, and R. DeFronzo. 1980. The role of fractional glucose extraction in the regulation of splanchnic glucose metabolism in normal and diabetic man. Metabolism. 29:28-35.

19. Ishida, T., Z. Chap, J. Chou, R. Lewis, C. Hartley, M. Entman, and J. B. Field. 1983. Differential effects of oral, peripheral intravenous, and intraportal glucose on hepatic glucose uptake and insulin and glucagon extraction in conscious dogs. J. Clin. Invest. 72:590-601.

20. Barrett, E. J., E. Ferrannini, R. Gusberg, S. Bevilacqua, and R. A. DeFronzo. 1985. Hepatic and extrahepatic splanchnic glucose metabolism in the postabsorptive and glucose fed dog. Metabolism. 34:410-420.

21. Adkins-Marshall, B. A., S. R. Myers, G. K. Hendrick, P. E. Williams, K. Triebwasser, B. Floyd, and A. D. Cherrington. 1990. Interaction between insulin and glucose delivery route in the regulation of net hepatic glucose uptake in conscious dogs. Diabetes. 39:87-95.

22. Bergman, R. N., J. R. Beir, and P. M. Hourigan. 1982. Intraportal glucose infusion matched to oral glucose absorption: lack of evidence for "gut factor" involvement in hepatic glucose storage. Diabetes. 31:27-35

23. Chiasson, J. L., J. E. Liljenquist, B. C. Sinclair-Smith, and W. W. Lacy. 1975. Gluconeogenesis from alanine in normal post-absorptive man: intrahepatic stimulatory effect of glucagon. Diabetes. 24:574-584.

24. Goresky, C. A., C. G. Back, and B. E. Nadeau. 1975. Red cell carriage of label: its limiting effect on the exchange of materials in the liver. Circ. Res. 36:328-351.

25. Kadish, A. H., R. L. Little, and J. C. Sternberg. 1968. A new and rapid method for the determination of glucose by measurement of rate of oxygen consumption. Clin. Chem. 14:116-131.

26. Lloyd, B., J. Burrin, P. Smythe, and K. G. M. M. Alberti. 1978. Enzymic fluorometric continuous-flow assays for blood glucose, lactate, pyruvate, alanine, glycerol, and 3-hydroxybutyrate. Clin. Chem. 24:1724-1729.

27. Brun, C. 1951. A rapid method for the determination of para-aminohippuric acid in kidney function tests. J. Lab. Clin. Med. 37:955-958.

28. Morgan, C. R., and A. L. Lazarow. 1963. Immunoassay of insulin: two antibody system. Plasma insulin of normal, subdiabetic and diabetic rats. Diabetes. 12:115-126.

29. Aguilar-Parada, E., A. M. Eisentraut, and R. H. Unger. 1969. Pancreatic glucagon secretion in normal and diabetic subjects. Am. J. Med. Sci. 257:415419.

30. Leevy, C. M., C. L. Mendenhall, W. Lesko, and M. M. Howard. 1962 Estimation of hepatic blood flow with indocyanine green. J. Clin. Invest. 41:1169-1179.

31. Greenway, C. V., and R. D. Stark. 1971. Hepatic vascular bed. Physiol. Rev. 51:23-65.

32. Snedecor, G. W., and W. G. Cochran. 1967. Statistical Methods. 6th ed. Iowa State University Press, Ames, IA.

33. Friedman, B., E. H. Goodman, Jr., and S. Weinhouse. 1967. Effects of glucose feeding, cortisol, and insulin on liver glycogen synthesis in the rat. Endocrinology. 81:486-496.

34. DeWulf, H., and H. G. Hers. 1967. The stimulation of glycogen synthesis and of glycogen synthetase in the liver by the administration of glucose. Eur. J. Biochem. 2:50-56.

35. Buschiazzo, H., J. H. Exton, and C. R. Park. 1970. Effects of glucose on glycogen synthetase, phosphorylase, and glycogen deposition in the perfused rat liver. Proc. Natl. Acad. Sci. USA. 65:383-387.

36. Ciudad, C. J., A. Carabaza, and J. J. Guinovart. 1986. Glucose 6-phosphate plays a central role in the activation of glycogen synthase by glucose in hepatocytes. Biochem. Biophys. Res. Commun. 141:1195-1200.

37. Newgard, C. B., D. W. Foster, and J. D. McGarry. 1984. Evidence for suppression of hepatic glucose-6-phosphatase with carbohydrate feeding. Diabetes. 33:192-195.

38. Eaton, R. P., R. C. Allen, and D. S. Schade. 1983. Hepatic removal of insulin in normal man: dose response to endogenous insulin secretion. J. Clin. Endocrin. Metab. 56:1294-1300.

39. Kaden, M., P. Harding, and J. B. Field. 1973. Effect of intraduodenal glucose administration on hepatic extraction of insulin in the anesthetized dog. $J$. Clin. Invest. 52:2016-2028.

40. Polonsky, K., J. Jaspan, D. Emmanouel, K. Holmes, and A. R. Moossa 1983. Differences in the hepatic and renal extraction of insulin and glucagon in the dog: evidence for saturability of insulin metabolism. Acta Endocrinol. 102:420-427. 
41. Jaspan, J., and K. Polonsky. 1982. Glucose ingestion in dogs alters the hepatic extraction of insulin. J. Clin. Invest. 69:516-525.

42. Ferrannini, E. R. A. DeFronzo, and R. S. Sherwin. 1982. Transient hepatic response to glucagon in man: role of insulin and hyperglycemia. $A m$. $J$. Physiol. 242:E73-E81.

43. Myers, S. R., O. P. McGuinness, D. W. Neal, and A. D. Cherrington. 1991. Intraportal glucose delivery alters the relationship between net hepatic glucose uptake and insulin. J. Clin. Invest. 87:930-939.

44. Shulman, G. I., W. W. Lacy, J. E. Liljenquist, U. Keller, P. E. Williams, and A. D. Cherrington. 1980. Effect of glucose, independent of changes in insulin and glucagon secretion, on alanine metabolism in the conscious dog. J. Clin Invest. 65:496-505.

45. Myers, S., O. McGuinness, D. Neal, and A. D. Cherrington. 1988. Porta glucose delivery potentiates insulin effects on net hepatic glucose uptake (NHGU). Diabetes. 38:81 A. (Abstr.)

46. Adkins, B. A., S. R. Myers, G. K. Hendrick, P. E. Williams, K. Triebwasser, B. Floyd, and A. D. Cherrington. 1985. Interaction between insulin and the route of intravenous glucose delivery in the regulation of net hepatic glucose uptake in the conscious dog. Diabetes Res. Clin. Pract. Suppl. 1:10.

47. Pagliassotti, M. J., M. C. Moore, D. W. Neal, and S. Myers. 1990. Rate of portal glucose entry can alter net hepatic glucose uptake (NHGU) despite constant hepatic glucose and insulin loads. Diabetes. 39:84A. (Abstr.)

48. Chap, Z., T. Ishida, J. Chou, R. Lewis, C. Hartley, M. Entman, and J. B. Field. 1985. Effects of atropine and gastric inhibitory polypeptide on hepatic glucose uptake and insulin extraction in conscious dogs. J. Clin. Invest. 76:1174 1181
49. Shimazu, T. 1967. Glycogen synthetase activity in liver: regulation by the autonomic nerves. Science (Wash. DC). 156:1256-1257.

50. Mondon, C. E., and S. D. Burton. 1971. Factors modifying carbohydrate metabolism and effect of insulin in perfused rat liver. Am. J. Physiol. 220:724734.

51. Ottolenghi, C., A. Caniato, and O. Barnabei. 1971. Effect of acetylcholine on glycogen formation and the activity of glycogen synthetase in isolated, perfused rat liver. Nature (Lond.). 229:420-422.

52. Shimazu, T. 1971. Regulation of glycogen metabolism in liver by the autonomic nervous system. V. Activation of glycogen synthetase by vagal stimulation. Biochim. Biophys. Acta. 252:28-38.

53. Shimazu, T., and T. Fujimoto. 1971. Regulation of glycogen metabolism in liver by the autonomic nervous system. IV. Neural control of glycogen biosynthesis. Biochim. Biophys. Acta. 252:18-27.

54. Akpan, J. O., R. Gardner, and S. R. Wagle. 1974. Studies on the effects of insulin and acetylcholine on activation of glycogen synthase and on glycogenesis in hepatocytes isolated from normal fed rats. Biochem. Biophys. Res. Commun. 61:222-229.

55. Lautt, W. W., and C. Wong. 1978. Hepatic parasympathetic neural effect on glucose balance in the intact liver. Can. J. Physiol. Pharmacol. 56:679-682.

56. Niijima, A. 1985. Blood glucose levels modulate efferent activity in the vagal supply to the rat liver. J. Physiol. 364:105-112.

57. Adkins-Marshall, B. A., J. Asher, S. Myers, C. Connolly, G. Moore, D. Neal, P. Williams, and A. D. Cherrington. 1988. Involvement of the CNS in the response of the liver to portal glucose delivery. Diabetologia. 31:462A. (Abstr.) 